\title{
Clinical assessment of quality of life of the patients with chronic blood transfusion and chelation therapy
}

Background: The patient with hemoglobinopathy like thalassemia major (TM), bone marrow dysfunction, and sickle cell disease are requiring chronic blood transfusion for their life time to survive. Among these, TM is one of the most common hemoglobinopathy worldwide. Objective: This study is done to assess the quality of life (QOL) of the patients with chronic blood transfusion and chelation therapy. Materials and Methods: The QOL scores were obtained through the selfadministered SF-36 questionnaire. The study subjects were asked to answer the SF-36 questionnaire once every 3 months. Results: After 6 months, the SF 36 general health mean score was $63.58 \pm 12.98(P<0.05)$. The highest mean score was $69.37 \pm 11.61$. The mean difference after the final reviews was statistically significant. Conclusion: The preponderance of scores used to assess QOL suggests that there is a direct and independent effect on $\mathrm{QOL}$ when treated with transfusion and iron-chelation therapy.

Key words: Blood transfusion, chelation therapy, quality of life

Tamil Selvan, Kingston Rajiah', Abhay Dharamsi', Vijaya Raghavan ${ }^{2}$

Departments of Pharmacy Practice, Karpagam University, Coimbatore, India, ${ }^{1}$ International Medical University, Malaysia, ${ }^{2}$ Department of Pharmaceutics, Periya Veedu Sama Govindadamy Naidu College of Pharmacy, Coimbatore, India

Address for the Correspondence:

Tamil Selvan, Departments of Pharmacy Practice, Karpagam University, Coimbatore, 642120, India. E-mail: tamizh@rediffmail.com

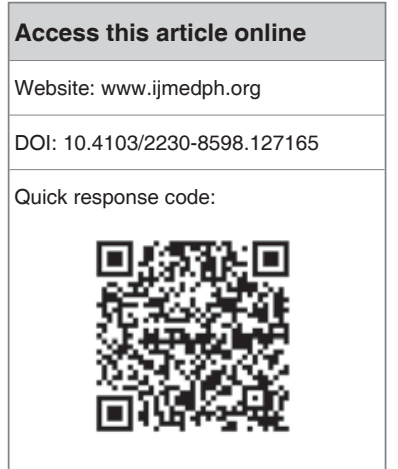

\section{INTRODUCTION}

The patient with hemoglobinopathy like Thalassemia major (TM), Bone marrow dysfunction, and Sickle cell disease are requiring chronic blood transfusion in their life time to survive. Among these, TM is one of the most common hemoglopinopathy in world wide. The purpose of the blood transfusion is to restore the blood hemoglobin $(\mathrm{Hb})$ level and to eliminate the complication of TM. State that patient are transfused at an early age may develop complications of iron overload in tissues, blood transfused infections, heart failure, diabetes mellitus, liver fibrosis, delayed puberty and growth retardation. ${ }^{[1,2]}$ Iron chelators like desferrioxamine and defriprone are used to eliminate the toxic iron load and reduce the complications of iron overload in tissues since introduction of iron chelators, the mortality and morbidity rate associated with thalassemia have been significantly reduced. ${ }^{[3]}$ The quality of life (QOL) is one of the important indexes of effective treatment. QOL is a focused study on the individual's views on their well-being and aspect of life. A model of QOL is proposed that integrates objective and subjective indicators, a broad range of life domains, and individual values. It takes account of concerns that externally derived norms should not be applied without reference to individual differences. It also allows for objective comparisons to be made between the situations of particular groups and what is normative. Considerable agreement exists that QOL is multidimensional. Coverage may be categorized within five dimensions: Physical well-being, material well-being, social well-being, emotional well-being, and development and activity. ${ }^{[4]}$

The SF-36 questionnaire yields an eight-scale profile of functional health and well-being scores as well as psychometrically-based physical and mental health summary measures and a preference-based health utility index. Accordingly, the SF-36 has proven useful in surveys of general and specific populations, comparing the relative burden of diseases, and in differentiating the health benefits produced by a wide range of different treatments. ${ }^{[5-8]}$

\section{Objective}

QOL is a focused study on the individual's views on their wellbeing and aspect of life. This study is done to assess the QOL of the patients with chronic blood transfusion and chelation therapy. 


\section{MATERIALS AND METHODS}

This prospective study was performed on transfusion dependent patient with hemoglobinopathy in the Department of Transfusion Medicine at Government General Hospital, Guntur, Andhra Pradesh India. The study was approved by Institutional Review Board. The inclusion criteria were both genders with the age more than 5 years, a diagnosis of hemoglobinopathy having more than 20 blood transfusions so far. Patient with bone marrow transplantation and the history of chronic disease like chronic obstructive pulmonary disease (COPD) and acquired immunodeficiency syndrome (AIDS) were excluded from the study. In total 147 patients were interviewed, 142 qualified, and 137 completed the study. The QOL scores were obtained through the self-administered questionnaire. These patients were assessed once in every 3 months with SF-36 questionnaire. Patient who were unable to answer the questionnaire were assisted by their parents or guardians. The subject's medical record was reviewed to assess the morbidity associated with chronic blood transfusion. $\mathrm{Hb}$ threshold of $6.0-7.0 \mathrm{~g} / \mathrm{dl}$ was the baseline.

\section{Outcome measures}

The SF-36 questionnaire is a self-administered health status measure that is widely accepted and validated..$^{[9]}$ It consists of 36 questions in eight dimensions such as physical function, physical health, role emotional, energy/fatigue, emotional well-being, social functioning, pain, and general health. All questions are scored on a scale from 0 to 100, with 100 representing the highest level of functioning possible. The mean scores of SF 36 for each patient at 0 month are underlined as a baseline score. This baseline score is used to evaluate the difference in mean scores after every 3 months for a period of 6 months.

\section{Statistical analysis}

Documented data was analyzed by using analysis of variance (ANOVA). Statistical significance was taken at 95\% level $(P<0.05)$. Results were expressed as mean \pm standard deviation (SD).

\section{RESULTS}

\section{Primary variables}

Out of 137 patients, most of them belong to the age group between 10 and 15 years $(42.3 \%)$. Male $(67.1 \%)$ patients were greater than the female $(32.9 \%)$ patients. Most of the patients have the family history of hemoglobinopathy $(66.4 \%)$ [Table 1].

\section{Physical function}

The mean baseline score of SF-36 physical function was $62.87 .87 \pm$ 23.58. The mean score difference was not statistical significant after 3 months $(63.14 \pm 21.02)$. However, at final review mean score $(73.72 \pm 21.98)$ showed statistical significant from the base line mean score $(P<0.05)$.

\section{Role physical health}

The mean baseline score of SF-36 role physical health was $43.75 \pm$ 11.57. The mean score difference was statistical significant after

\begin{tabular}{lcc} 
Table 1: Demographic characteristics of the study \\
sample $(\boldsymbol{n}=\mathbf{1 3 7})$ \\
\hline Characteristic & No & $\%$ \\
\hline Age (years) & & \\
5-10 & 42 & 30.6 \\
10-15 & 58 & 42.3 \\
$\quad$ More than 15 & 37 & 27.1 \\
Sex & & \\
$\quad$ Male & 98 & 67.1 \\
Female & 39 & 32.9 \\
Family history of hemoglobinopathy & & \\
Yes & 91 & 66.4 \\
No & 40 & 29.1 \\
Do not know & 06 & 04.5 \\
\hline
\end{tabular}

3 months $(50.00 \pm 18.89)(P<0.05)$. The final review mean score $56.87 \pm 12.32$ showed statistical significant from the baseline mean score $(P<0.05)$.

\section{Role emotional}

The mean baseline score of SF-36 role emotional was $58.50 \pm$ 21.57. The mean score difference was statistical significant at every review. The final review mean score $65.96 \pm 21.96$ showed statistical significant from the baseline mean score $(P<0.05)$.

\section{Energy/fatigue}

The final review mean score of SF-36 energy/fatigue was 43.75 \pm 11.57 . The mean score was statistically significant form baseline mean score of $72.32 \pm 19.94(P<0.05)$. The first review mean score $(59.32 \pm 17.69)$ which did not show statistical significant from the baseline mean score.

\section{Emotional well-being}

After 6 months, SF-36 emotional well-being mean score was 63.83 $\pm 21.52(P<0.05)$. The final review mean score $71.69 \pm 22.46$ $(P<0.05)$ was showed statistical significant from the baseline mean score of $56.22<17.39$.

\section{Social functioning}

The highest mean score of SF-36 social functioning was $75.69 \pm$ $21.32(P<0.05)$ which was obtained after 9 months. The mean base line score was $62.22 \pm 32.25$.

\section{Pain}

The mean score $54.81 \pm 21.25$ at final review was not statistically significant with baseline mean score of $52.64 \pm 24.43$.

\section{General health}

After 6 months the SF-36 general health mean score was 63.58 $\pm 12.98(P<0.05)$. The highest mean score was $69.37 \pm 11.61$. The mean difference after the final reviews was statistically significant. 


\begin{tabular}{lcc} 
Table 2: Comorbidity assessment & \\
\hline Comorbidity & No of patients & Percentage \\
\hline Hepatitis & 41 & 29.9 \\
Injection site infection/allergy & 12 & 08.7 \\
Cardiomyopathy & 3 & 02.1 \\
Jaundice & 11 & 08.4 \\
Lymphadenopathy & 7 & 05.1 \\
Hypothyroidism & 2 & 01.4 \\
Vertigo & 5 & 03.6 \\
Headache & 48 & 35.0 \\
Anxiety & 8 & 05.8 \\
\hline
\end{tabular}

\section{Comorbidity assessment}

Out of 137 patients, 35\% had headache which is high among other comorbidities. $29.9 \%$ had hepatitis; injection site infection/ allergy was $8.7 \%$. Cardiomyopathy, jaundice, lymphadenopathy, hypothyroidism, and vertigo also reported. Refer [Table 2].

\section{DISCUSSION}

In developing countries TM has become a major health problem. ${ }^{[10]}$ TM is usually recognized in childhood, at which time patient begin treatment with blood transfusion to maintain $\mathrm{Hb}$ level and chelation therapy to overcome iron overload in tissues later. This study results support the other studies on the QOL of TM patent with other chronic disease like hepatitis, hypothyroidism, ulcerative colitis, cystic fibrosis, congenital heart disease, epilepsy, and diabetes. ${ }^{[11]}$ Very good scores were obtained for the physical, emotional, role, and social function domains. In the current study, we found that patients rated their overall health significantly better with transfusion and ironchelation therapy. The differences were mainly found in perceived physical health that they considered themselves less dependent on other and medical aids, having good energy and less fatigue in their daily activity. The regimen of iron chelation probably has significant influence on the QOL of conventionally treated patients. The current study has demonstrated that patient on chronic blood transfusion with chelation therapy had significantly better self-rated QOL in physical mental and social domains.

\section{CONCLUSION}

The measurement of health-related QOL is fraught with methodological difficulties, and comparison across is often impossible. But the preponderance of scores used to assess QOL suggests that there is a direct and independent effect on QOL when treated with transfusion and iron-chelation therapy. We often do not have the capacity to cure disease, but we can focus on improving symptom complexes, such as fatigue, lack of energy, and functional capacity.

\section{Limitations}

$\mathrm{Hb}$ threshold of $6.0-7.0 \mathrm{~g} / \mathrm{dL}$ was the baseline. This recommendation, however, may not take into account the range of potentially normal $\mathrm{Hb}$ concentrations. For example, it assumes that a man with a baseline $\mathrm{Hb}$ concentration of $18 \mathrm{~g} / \mathrm{dL}$ and a woman with a baseline $\mathrm{Hb}$ concentration of $12 \mathrm{~g} / \mathrm{dL}$ will have a similar tolerance to an acute decrease in $\mathrm{Hb}$ to $7.0 \mathrm{~g} / \mathrm{dL} \cdot{ }^{[12]}$

\section{REFERENCES}

1. Lo L, Singer ST. Thalassemia: Current approach to an old disease. Pediatr Clin North Am 2002;49:1165-91.

2. Gabutti V, Borgna-Pignatti C. Clinical manifestations and therapy of transfusional haemosiderosis. Baillieres Clin Haematol 1994;7:919-40.

3. Felce D, Perry J. Quality of life: Its definition and measurement. Res Dev Disabil 1995;16:51-74.

4. Pakbaz Z, Treadwell M, Yamashita R, Quirolo K, Foote D, Quill L, et al. Quality of life in patients with thalassemia intermedia compared to thalassemia major. Ann N Y Acad Sci 2005;1054:457-61.

5. Finn SD. The quest to quantify quality. JAMA 2000;283:1740-2.

6. Stewart AL, Greenfield S, Hays RD, Wells K, Rogers WH, Berry SD, et al. Functional status and well being of patients with chronic conditions. JAMA 1989;262:907-13.

7. Riesenberg D, Glass RM. The Medical outcomes study. JAMA 1989;262:943.

8. Ferrell BR, Wisdom C, Wenzl C. Quality of life as an outcome variable in the management of cancer pain. Cancer 1989;63:2321-7.

9. Jafari H, Lahsaeizadeh S, Jafari P, Karimi M. Quality of life in thalassemia major: Reliability and validity of the Persian version of the SF-36 questionnaire. J Postgrad Med 2008;54:273-5.

10. Montazeri A, Goshtasebi A, Vahdaninia M, Gandek B. The short form health survey: Translation and validation study of Iranian version. Qual Life Res 2005;14:875-82.

11. Jarman F, Oberklaid F. Children with chronic illness: Factors affecting psychosocial adjustment. Current Opinion Ped 1990;2:868-72.

12. Karkouti K, Wijeysundera DN, Yau TM, McCluskey SA, van Rensburg A, Beattie WS. The influence of baseline hemoglobin concentration on tolerance of anemia in cardiac surgery. Tranfusion 2008;48:666-72.

How to cite this article: Selvan T, Rajiah K, Dharamsi A, Raghavan V. Clinical assessment of quality of life of the patients with chronic blood transfusion and chelation therapy. Int $\mathrm{J}$ Med Public Health 2014;4:88-90.

Source of Support: Nil, Conflict of Interest: None declared. 